\title{
Insulin receptor substrate 1 regulates the cellular differentiation and the matrix metallopeptidase expression of preosteoblastic cells
}

\author{
Yan-Hong Bu ${ }^{1,2, *}$, Yu-Ling He ${ }^{1, *}$, Hou-De Zhou ${ }^{1}$, Wei Liư ${ }^{1}$, Dan Peng ${ }^{3}$, Ai-Guo Tang² , Ling-Li Tang² , \\ Hui Xie ${ }^{1}$, Qiu-Xia Huang ${ }^{1}$, Xiang-Hang Luo ${ }^{1}$ and Er-Yuan Liao ${ }^{1}$ \\ ${ }^{1}$ Institute of Metabolism and Endocrinology, ${ }^{2}$ Department of Clinical Laboratory and ${ }^{3}$ Department of Orthopaedics, The Second Xiang-Ya Hospital of Central \\ South University, 410011 ChangSha, People's Republic of China \\ (Correspondence should be addressed to H-D Zhou; Email: houdezhou@xysm.net) \\ *(Y-H Bu and Y-L He contributed equally to this work)
}

\begin{abstract}
Insulin receptor substrate 1 (IRS1) is an essential molecule for the intracellular signaling of IGF1 and insulin, which are potent anabolic regulators of bone metabolism. Osteoblastic IRS1 is essential for maintaining bone turnover; however, the mechanism underlying this regulation remains unclear. To clarify the role of IRS1 in bone metabolism, we employed RNA interference to inhibit IRS1 gene expression and observed the effects of silencing this gene on the proliferation and differentiation of and the expression of matrix metallopeptidase (MMP) and tumor necrosis factor receptor superfamily, member 11b (TNFRSF11B) in MC3T3-E1 cells. Our results showed that IRS1 short hairpin RNAs can effectively suppress the expression of IRS1, and inhibit the
\end{abstract}

phosphorylation of AKT in IRS1 pathway; reduce the expression of MMP2, MMP3, MMP13, and MMP14, decrease the expression of TNFRSF11B and RANKL (also known as tumor necrosis factor (ligand) superfamily, member 11), however increase the RANKL/TNFRSF11B ratio; decrease cell survival, proliferation, and mineralization, and impair the differentiation of MC3T3-E1 cells. The downregulation of IRS1 had no effect on the expression of MMP1. Our findings suggest that IRS1 not only promotes bone formation and mineralization but also might play roles in bone resorption partly via the regulation of MMPs and RANKL/TNFRSF11B ratio, thus regulates the bone turnover.

Journal of Endocrinology (2010) 206, 271-277

\section{Introduction}

Insulin receptor substrates (IRSs) are essential for receptor tyrosine kinases, such as insulin and insulin-like growth factor 1 (IGF1) receptors, as well as other cytokines affecting cellular function (Burks \& White 2001). Following stimulation by a ligand, the IRSs are rapidly phosphorylated on multiple tyrosine residues (Kadowaki et al. 1996). The phosphorylated substrates bind to proteins containing Src homology 2 domains, and then activate phosphoinositide 3-kinase and mitogen-activated protein kinase pathways to regulate cell differentiation, growth, and metabolism (Cusi et al. 2000). The mammalian IRS family contains at least four members: ubiquitous IRS1 and IRS2, adipose tissuepredominant IRS3, and IRS4, which is expressed in the thymus, brain, and kidney (Sun et al. 1991, 1995). Studies have shown that IRS1 and IRS2 are expressed in bone tissue (Akune 2004). Irs 1 gene knockout mice (Irs $1^{-1-}$ mice) and Irs 2 gene knockout mice (Irs $2^{-/-}$mice) showed osteopenia that developed via different cellular mechanisms: in the case of the Irs $1^{-1-}$ mice, both bone formation and resorption were decreased (Ogata et al. 2000), whereas in the Irs $2^{-1-}$ mice, decreased bone formation and increased bone resorption were noted (Akune et al. 2002). Therefore, IRS1 is indispensable for maintaining the bone turnover, while IRS2 is essential for retaining the predominance of bone formation over bone resorption, and plays important roles in $17 \beta$-estradiol induced bone formation ( $\mathrm{Bu}$ et al. 2009).

Matrix metallopeptidases (MMPs) belong to a family of zinc endopeptidases that are capable of degrading most of the structural components of the extracellular matrix ( $\mathrm{Ra} \&$ Parks 2007). MMPs promote bone resorption by facilitating the attachment of osteoclasts to the bone and removing unmineralized matrix from the bone surface (Rifas et al. 1994, Manduca et al. 2009). IRS1 is expressed in osteoblasts but not in osteoclasts, the decrease in bone resorption in the Irs $1^{-/-}$ mice is caused by a defect in the osteoblasts that support osteoclast differentiation, and is not due to the intrinsic abnormalities of osteoclast progenitors or the reduced activity/ survival of mature osteoclasts (Ogata et al. 2000). MMPs function as 'coupling factors' that allow osteoblasts to exert a regulatory effect on osteoclast resorptive activity. Evidence has shown that IRS2 down-regulated MMP13 expression and inhibited osteoclastogenesis (Akune et al. 2002). 
Our previous studies have shown that osteoblasts can also express the MMPs (Li et al. 2004); however, it is not clear whether IRS1 affects MMPs expression and regulates bone turnover. The receptor activator of NF- $\mathrm{KB}$ ligand (RANKL)/RANK/ tumor necrosis factor receptor superfamily, member $11 \mathrm{~b}$ (TNFRSF11B) system is now recognized as the dominant pathway regulating bone resorption (Gallagher 2008). RANKL is a cytokine belonging to the tumor necrosis factor family and is expressed by osteoblasts; it binds to the membrane-bound receptor RANK on osteoclasts and promotes the differentiation of the marrow cells to multinucleated osteoclasts through various stages (Yamaguchi \& Uchiyama 2004). TNFRSF11B is a soluble receptor that is a potent antagonist of osteoclast formation, and it exerts its action by binding and inactivating the RANKL (Boyce \& Xing 2007). IRS1 regulates the bone turnover, but the effect of IRS1 on the RANKL/RANK/ TNFRSF11B system remains unclear. In this study, we used RNA interference to silence the Irs 1 gene and observe the effects of Irs 1 on cell proliferation, differentiation, and the expression of MMPs and RANKL/RANK/TNFRSF11B in murine preosteoblastic MC3T3-E1 cells.

\section{Materials and Methods}

\section{Cell culture}

The murine preosteoblastic MC3T3-E1 cells were routinely cultured in phenol red-free DMEM (Sigma) containing 10\% fetal bovine serum (FBS, Invitrogen) and $50 \mu \mathrm{g} / \mathrm{ml}$ ascorbic acid (Sigma) at $37^{\circ} \mathrm{C}$ in a humidified atmosphere containing $5 \% \mathrm{CO}_{2}$. The medium was changed two to three times per week.

\section{Plasmid construction}

Short hairpin RNA (shRNA) plasmids were constructed by and purchased from Genesil Biotechnology Corporation (Wuhan, People's Repubic of China). We designed three coding sequences (target 1135-1155, 1429-1447, and 4432-4452 to murine Irs 1 mRNA; Genbank accession number: NM_010570) for the shRNAs. Subsequently, these three coding sequences were inserted into the pGenesil-1 vector, which has a neomycin- and kanamycin-resistant gene and expresses the enhanced green fluorescent protein; these sequences were designated as Irs 1 shRNA1, Irs 1 shRNA2, and Irs 1 shRNA3 respectively, and were analyzed by BLAST search to ensure that they did not have significant sequence homology with other genes. One scramble shRNA was inserted into the pGenesil-1 vector as the negative control (denoted as HK shRNA). The loop sequence for all the shRNAs was TTCAAGACG. All the shRNA plasmids can stably express the shRNA when they were stably transfected into cells.

\section{Transfection and selection of stably transfected MC3T3-E1 cells}

Before the transfections, MC3T3-E1 cells were seeded in six-well plates at a density of $1 \times 10^{5}$ cells/well. The transfections with the shRNAs were performed using the Lipofectamine 2000 transfection kit (Invitrogen) as per the manufacturer's instructions. Two days after the transfection, the cells were replated at a lower density and selected using a media containing $500 \mu \mathrm{g} / \mathrm{ml}$ geneticin (G418) for 21 days until discrete colonies were formed. Individual colonies were isolated and grown, and then semi-quantitative reverse transcription PCR (RT-PCR) and western blotting were used to test the inhibition efficiency of IRS1 gene expression. Stably transfected MC3T3-E1 (ST-MC3T3-E1) cells were sustained in a medium containing $200 \mu \mathrm{g} / \mathrm{ml} \mathrm{G418}$ and $10 \%$ FBS. Because insulin at $1.0 \mathrm{U} / \mathrm{ml}$ level has been shown to stimulate growth of cells in media containing $10 \%$ FBS (Webber 1980), no additional insulin was added to the medium in future studies.

\section{von Kossa staining}

The MC3T3-E1 cells transfected with HK shRNA and Irs1 shRNAs were treated with $100 \mathrm{nM}$ dexamethasone, $50 \mu \mathrm{g} / \mathrm{ml} \mathrm{L}$-ascorbic acid, and $5 \mathrm{mM} \beta$-glycerophosphate, and the medium was replaced every $2-3$ days. The mineral deposition of the bone-specific extra cellular matrix was determined by von Kossa staining for calcium. Briefly, cells were fixed with 3\% paraformaldehyde for $10 \mathrm{~min}$, stained with $\mathrm{AgNO}_{3}$, rinsed with distilled water, exposed for $1.5 \mathrm{~h}$ to bright light, and counterstained with nuclear fast red for $5 \mathrm{~min}$, and finally observed by transmitted light microscopy; the surface area of the cell cultures occupied by mineralized nodules was compared in each well as described previously (Rowe et al. 1999).

3-[4,5-dimethylthiazol-2-yl]-2,5-diphenyl tetrazolium bromide and $\left[{ }^{3} \mathrm{H}\right]$-thymidine incorporation assays to determine cell survival and proliferation

MC3T3-E1 cells were seeded in 96-well plates at a density of $1 \times 10^{4} /$ well; after $24 \mathrm{~h}$ of culture, the medium was removed, and $200 \mu \mathrm{l}$ of $0.5 \mathrm{mg} / \mathrm{ml}$ 3-[4,5-dimethylthiazol-2-yl]-2, 5 -diphenyl tetrazolium bromide in DMEM were added to each well and incubated for $4 \mathrm{~h}$ at $37^{\circ} \mathrm{C}$. Formazan crystals were dissolved in $150 \mu \mathrm{l}$ of dimethyl sulfoxide, and the absorbance at $570 \mathrm{~nm}$ was measured. The cell survival ratio was calculated according to the following formula: survival ratio $=A_{\text {treat }} / A_{\text {control }} \times 100 \%$. For $\left[{ }^{3} \mathrm{H}\right]$-thymidine incorporation assay, cells were incubated in 24-well plates at a density of $5 \times 10^{4} /$ well. After 24 h of culture, $\left[{ }^{3} \mathrm{H}\right]$-thymidine $(1 \mu \mathrm{Ci} / \mathrm{ml}$ in the medium) was added to the medium, and the cells were cultured for a further $8 \mathrm{~h}$; radioactivity was determined using a liquid scintillation counter (Wallac OY, Turku, Finland).

Flow cytometry and acridine orange/ethidium bromide staining assay to determine apoptosis

MC3T3-E1 cells transfected with HK shRNA and Irs1 shRNAs were seeded in six-well plates at a density of $5 \times 10^{4} /$ well. After the cells reached about $50-60 \%$ 


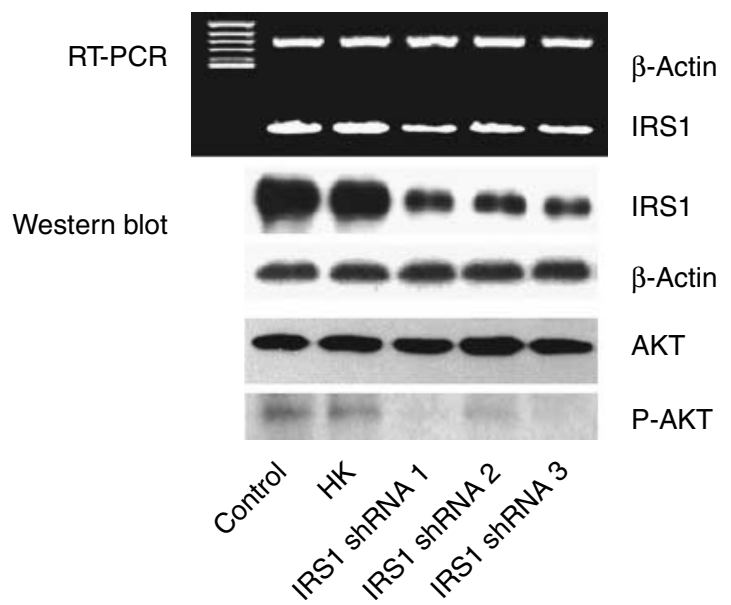

Figure 1 The effects of insulin receptor substrate 1 (Irs1) gene silencing (by Irs 1 shRNA1, 2, and 3 transfection) on the phosphorylation of AKT in MC3T3-E1 preosteoblast cells. IRS1 expression level in MC3T3-E1 cells was efficiently down-regulated by shRNA transfection as determined by reverse transcription PCR (RT-PCR) and western blot; the phosphorylation of AKT, which is the target molecule in IRS pathway induced by IGF1, was decreased by Irs1 gene silencing.

confluence, serum was deprived for $24 \mathrm{~h}$. Cells were then labeled using the nucleic acid-binding dye mix of $100 \mu \mathrm{g} / \mathrm{ml}$ acridine orange and $100 \mu \mathrm{g} / \mathrm{ml}$ ethidium bromide (Sigma) in PBS. The cells were examined by fluorescent microscopy. Viable cells had green fluorescent intact nuclei, while the apoptotic cells had orange chromatin with highly condensed or fragmented nuclei. The necrotic cells had bright orange chromatin and round nuclei. Only the cells with yellow, condensed, or fragmented nuclei samples were counted as apoptotic cells. For flow cytometric analysis, MC3T3-E1 cells transfected with HK shRNA and Irs 1 shRNAs were seeded into $25 \mathrm{~cm}^{2}$ flasks at a density of $1 \times 10^{5} / \mathrm{ml}$ and cultured to $50-60 \%$ confluence. The cells were deprived of serum for $24 \mathrm{~h}$, and then digested by $0 \cdot 25 \%$ trypsin-EDTA. We fixed the cells by using ice-cold 95\% ethanol and measured apoptosis by flow cytometric analysis in Dingguo Biotechnologies Inc. (Beijing, People's Republic of China).

\section{Analyses of alkaline phosphatase activity and osteocalcin}

MC3T3-E1 cells transfected with HK shRNA and Irs1 shRNAs were cultured in the medium with $10 \mathrm{mM}$ $\beta$-sodium glycerophosphate and $50 \mu \mathrm{g} / \mathrm{ml}$ of ascorbic acid. When the cells reached confluence, they were lyzed and sonicated for $20 \mathrm{~s}$. Alkaline phosphatase (ALP) activity in both the cell lysate and the culture media was measured in the three independent cultures using an ALP assay kit (Sigma). Osteocalcin released into the culture media was measured in triplicate using a specific RIA kit (DiaSorin Corp., Stillwater, MN, USA). To normalize protein levels in the culture media to the total cellular protein, the protein content in a fraction of the lysate solution was determined using the BCA protein assay reagent (Pierce, Rockford, IL, USA).

\section{Semi-quantitative RT-PCR}

Total RNA was isolated from each sample using Trizol reagent (Invitrogen) according to the manufacturer's recommended protocol. We performed RT using $1 \cdot 0 \mu \mathrm{g}$ total RNA and the RT system (Promega). The PCR primers of type I collagen were $5^{\prime}$-GAAGTCAGCTGCATACACAA- $3^{\prime}$ and $5^{\prime}$-GCTGATTTTTCATCATAGCC- ${ }^{\prime}$, yielding a 403-bp fragment. The PCR primers of IRS1 were $5^{\prime}$-GGTAAGCTCTTGCCTTGCAC- $3^{\prime}$ and $5^{\prime}$-TGTGTGAGGCTTGACTCTGG-3', yielding a 326-bp fragment. The PCR products of $\beta$-actin served as the internal control. The amplification cycles were 26, 29, and 25 respectively. The reactions were stopped at the exponential phase. The PCR products were run on a $1 \cdot 2 \%$ agarose gel, stained with ethidium bromide, and photographed under an u.v. illumination system. The primers were synthesized by Shanghai BioAsia Biotechnology Company, Ltd (Shanghai, People's Republic of China). In addition, the PCR products were extracted from the agarose gels and sequenced by BioAsia Company.

\section{Cell treatment and western blotting analysis}

To detect the phosphorylation of AKT, the direct target in IRS1 pathway, after the IRS1 shRNA transfection, the cells were starved for $24 \mathrm{~h}$ and then incubated in the absence or in the presence of $100 \mathrm{nmol} / \mathrm{l} \mathrm{IGF} 1$ for $15 \mathrm{~min}$ at $37^{\circ} \mathrm{C}$. At the end of incubation, the cells were rapidly washed with $\mathrm{Ca}^{2-} / \mathrm{Mg}^{2-}$ free PBS, and then mechanically detached in ice-cold lysis buffer $(50 \mathrm{mM}$ Tris- $\mathrm{HCl}, 150 \mathrm{mM} \mathrm{NaCl}$, $10 \mathrm{mM}$ EDTA, $0 \cdot 02 \%$ sodium azide, $1 \%$ Triton X-100, $1 \mathrm{mM}$ phenylmethylsulphonyl fluoride, and $10 \mu \mathrm{g} / \mathrm{ml}$ aprotinin, $\mathrm{pH} 8 \cdot 0$ ). The protein concentrate was determined using a BCA protein assay reagent (Pierce). The cell lysates

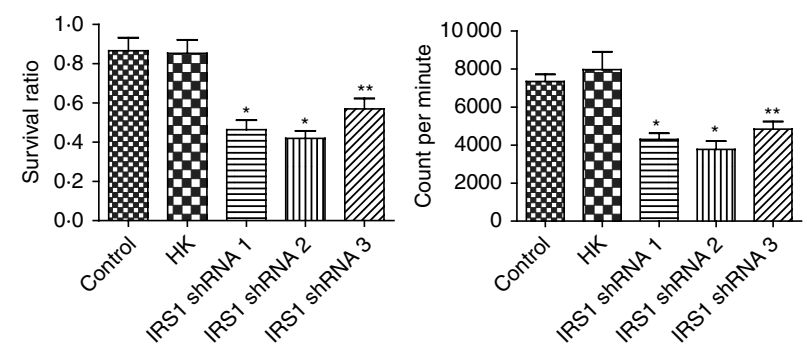

Figure 2 The effects of insulin receptor substrate 1 (Irs1) gene silencing on cell survival (left panel) and proliferation (right panel) in MC3T3-E1 cells. Cell survival was determined by MTT assay. Cell proliferation was determined by $\left[{ }^{3} \mathrm{H}\right]-\mathrm{TdR}$ incorporation assay. Data are expressed as mean (bars) \pm S.E.M. (error bars). Compared with untransfected (control) group and the HK group, $* P<0 \cdot 01$, $* * P<0 \cdot 05$. 


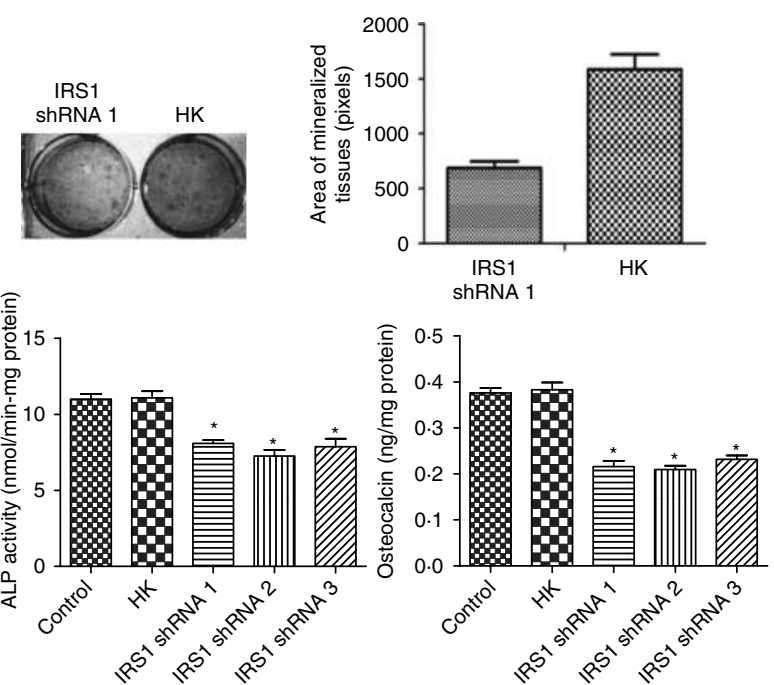

Figure 3 Effects of Irs1 gene silencing on the differentiation of MC3T3-E1 preosteoblast cells. von Kossa stain for mineralization, alkaline phosphatase activity, and osteocalcin secretion were detected in each group. Marked mineralization was seen in scramble shRNA-transfected (HK group) 3T3-E1 cells (black dots); however, mineralization was reduced in 3T3-E1 cells with Irs 1 gene silencing; Irs1 short hairpin RNA (shRNA) can reduce the ALP activity and osteocalcin secretion. Data are expressed as mean (bars) \pm s.E.M. (error bars). Compared with untransfected (control) group and the HK group, ${ }^{*} P<0 \cdot 05$.

containing an equivalent amount of protein $(30 \mu \mathrm{g})$ were electrophoresed by $8 \%$ SDS-PAGE and transferred to polyvinylidene fluoride membranes (Millipore, Billerica, MA, USA). After blocking with 5\% fat-free milk, the lysates were incubated with a rabbit anti-IRS1, MMP2, MMP13, MMP14, RANKL (Santa Cruz Biotechnology, Santa Cruz, CA, USA), AKT and phosphorylated AKT (Cell Signal, Danvers, MA, USA), goat anti-collagen I, mouse anti-MMP1 and TNFRSF11B (Santa Cruz Biotechnology), and then incubated with incubated peroxidase secondary antibody. Immunoreactive bands were stained using the enzymatic chemiluminescence reaction kit (Pierce). The same membrane was stripped, and then reprobed with a mouse monoclonal antibody against human $\beta$-actin (Sigma) as an internal control. The intensity of each band was measured by densitometry (Bio-Rad Laboratories). The target protein levels were calculated after standardization to the $\beta$-actin concentration and were expressed as the mean value of the three independent experiments.

\section{Statistical analyses}

Statistical significance was determined by Statistical Product and Service Solutions 13.0 for windows. Data are expressed as the mean \pm s.D. of mean. Statistical differences between mean values (derived from the same clone in several different wells for each experiment, and we repeated the experiment at least three times) were determined using one-way ANOVA and Student's t-test. $P<0 \cdot 05$ was considered statistically significant.

\section{Results}

IRS1 shRNA inhibits the AKT phosphorylation induced by IGF1 in MC3T3-E1 cells

The semi-quantitative RT-PCR and western blot analyses revealed that the expression levels of IRS1 mRNA and protein were significantly lower in the Irs 1 shRNA 1, 2, and 3 groups than those in the untransfected control and the HK shRNA groups (Fig. 1). All the three Irs 1 shRNAs effectively inhibited the expression and phosphorylation of AKT induced by IGF1 in MC3T3-El cells (Fig. 1).

The effects of IRS1 gene silencing on cell survival and proliferation in MC3T3-E1 cells

Compared with the untransfected control and the HK shRNA groups, the cell survival and proliferation rates were lower in the Irs 1 shRNA 1, 2, and 3 groups (Fig. 2) than the untransfected control and the HK shRNA groups; the percentage cell survival in Irs 1 shRNA 1, 2, and 3 groups is $42 \pm 13,40 \pm 5$, and $55 \pm 11 \%$ respectively. Therefore, our results indicate that Irs 1 shRNA 1 and shRNA 2 have greater abilities to inhibit the cell survival and proliferation of murine preosteoblasts than Irs 1 shRNA 3.
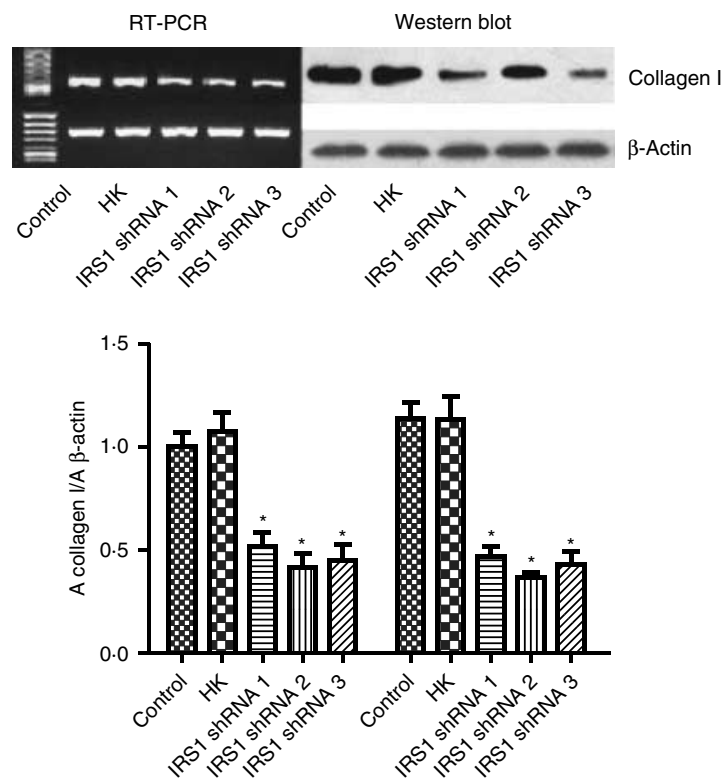

Figure 4 The effects of insulin receptor substrate 1 (Irs1) gene silencing on collagen mRNA and protein expression in MC3T3-E1 preosteoblastic cells. The bars represent the ratio of optical density values of collagen I mRNA and protein relative to that of $\beta$-actin measured by densitometry. Data are expressed as mean (bars) \pm s.E.M. (error bars). Compared with untransfected (control) group and the HK group, ${ }^{*} P<0 \cdot 01$. 

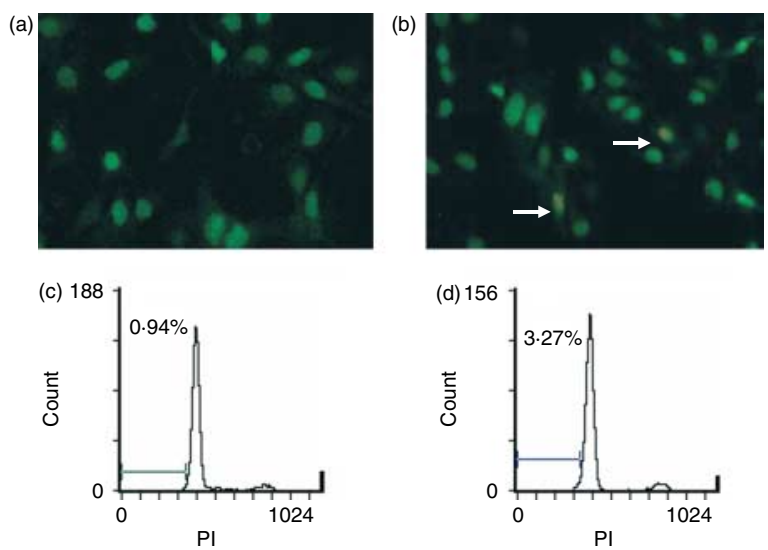

Figure 5 Effect of insulin receptor substrate 1 (Irs1) gene silencing on cell apoptosis in MC3T3-E1 cells. (a and c) HK group; (b and d), shRNA1 group. Cell apoptosis was assessed by acridine orange/ethidium bromide staining assay ( $\mathrm{a}$ and $\mathrm{b}$ ) and flow cytometric analysis. Magnification was the same for all micrographs $(\times 400)$. Arrows show the apoptotic cells with orange nuclei.

The effect of Irs1 gene silencing on cell differentiation and apoptosis in MC3T3-E1 cells

ALP activity and osteocalcin expression are important markers for osteoblast differentiation. The Irs 1 shRNA 1, 2, and 3 groups significantly decreased the ALP activity and osteocalcin levels in the MC3T3-E1 cells $(P<0 \cdot 05$, Fig. 3). The change of osteoblast differentiation potential after IRS1 silence was assessed by evaluating the mineralization of the cell cultures in the presence of osteogenic induction medium. Marked mineralization was seen in control 3T3-E1 cells; however, area of mineralized nodules was reduced in 3T3-E1 cells with Irs 1 gene silencing (Fig. 3); the mRNA and protein expressions of type I collagen were also down-regulated $(P<0 \cdot 01$, Fig. 4). IRS1 gene silencing also induced apoptosis in the MC3T3-E1 cells; the apoptotic cells had condensed and orange nuclei (Fig. 5b). The degree of apoptosis in the HK group and Irs 1 shRNA group was $1.03 \pm 0.32$ and $3.57 \pm 1.80 \%$ respectively (Fig. 5c and d).

The effect of Irs1 gene silencing on the expression of TNFRSF11B, RANKL, and MMPs in MC3T3-E1 cells

The expression levels of MMP2, MMP3, MMP13, and MMP14 were lower in the Irs 1 shRNA 1, 2, and 3 groups than the untransfected control and HK shRNA groups $(P<0 \cdot 05$, Fig. 6). However, no difference was observed in the expression of MMP1 among all the groups (Fig. 6). The TNFRSF11B and RANKL expression were also reduced in the Irs 1 shRNA 1,2 , and 3 groups $(P<0 \cdot 05$, Fig. 7), however, the ratio of RANKL to TNFRSF11B is up-regulated by $I r s 1$ gene silencing (Fig. 7).

\section{Discussion}

Bone remodeling is a spatially coordinated lifelong process, whereby old bone is removed by osteoclasts and replaced by bone-forming osteoblasts (Kearns et al. 2008). The TNFRSF11B/ RANK/RANKL system identified in the mid-1990s was thought to be one of the most important coupling factors between bone formation and resorption, which regulates the bone turnover (Hamdy 2007). IRS1, might also be an important coupling factors, was proved to regulate the bone turnover by performing research on the IRS 1 gene knockout mice (Ogata et al. 2000). Unlike the TNFRSF11B/RANKL/ RANK system, which regulates the bone turnover via both the osteoblast and osteoclast, the IRS1 regulates bone turnover mainly via the osteoblast, but the underlying mechanism is not clear.

To elucidate the mechanism underlying the regulation of bone turnover by the IRS1, we generated MC3T3-E1 cells stably transfected with the plasmids expressing shRNAtargeting murine Irs 1 gene, which allows the generation of stable cell lines with permanently reduced levels of the IRS1 protein. Our data showed that the three Irs 1 shRNAs targeting the nucleotides 1135-1155, 1429-1447, and 4432-4452 of the Irs 1 gene can inhibit Irs 1 mRNA and protein expression. Therefore, Irs 1 shRNAs provide a useful strategy for identifying the functions of IRS1. The downregulation of IRS1 expression not only reduced cell survival and proliferation, but also impaired cell differentiation in MC3T3-E1 cells (ALP activity and the expression of both

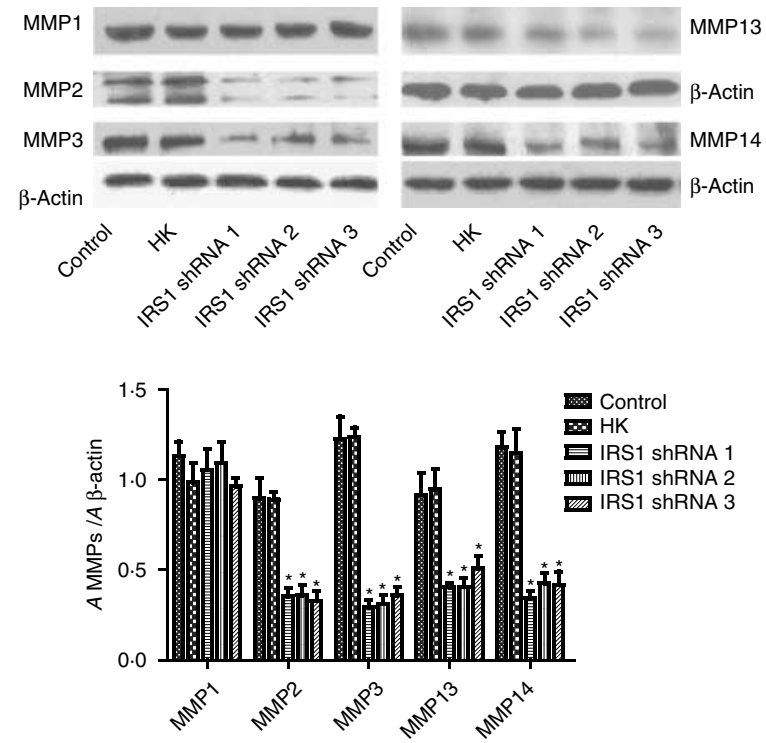

Figure 6 The effects of insulin receptor substrate 1 (Irs1) gene silencing on matrix metalloproteinases MMP1, MMP2, MMP3, MMP13, and MMP14 protein expression in MC3T3-E1 osteoblastlike cells. The bars represent the ratio of optical density values of each protein relative to that of $\beta$-actin measured by densitometry. Data are expressed as mean (bars) \pm s.E.M. (error bars). Compared with untransfected (control) group and HK group, $* P<0 \cdot 05$. 
A
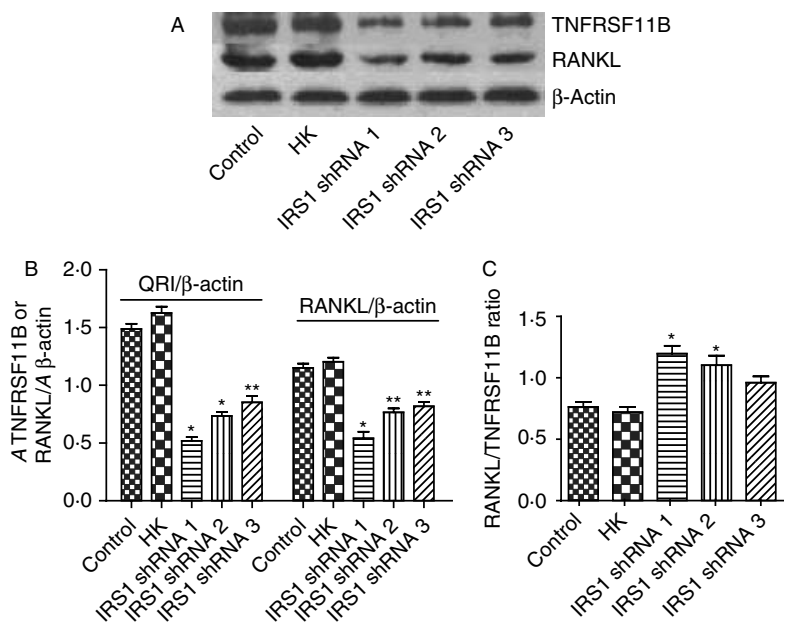

Figure 7 The effects of insulin receptor substrate 1 (Irs1) gene silencing on TNFRSF11B and receptor activator of NF- $\kappa \mathrm{B}$ ligand (RANKL) protein levels in MC3T3-E1 preosteoblast cells. The expression of TNFRSF11B and RANKL was down-regulated simultaneously by Irs1 silencing (A and B); however, RANKL/ TNFRSF11B ratio was increased (C). The bars in panel $B$ represent the ratio of optical density values of each protein relative to that of $\beta$-actin measured by densitometry, and bars in panel $C$ represent the ratio of RANKL to TNFRSF11B. Data are expressed as mean (bars) \pm s.E.M. (error bars). Compared with untransfected (control) group and HK group, ${ }^{*} P<0 \cdot 01,{ }^{* *} P<0 \cdot 05$.

osteocalcin and type I collagen mRNA and protein were all decreased), which suggested that IRS1 can increase the bone formation by promoting the proliferation and differentiation of preosteoblasts and increase the bone matrix by producing more collagen. Although the mechanism by which IRS1 increases the cell proliferation and differentiation needs to be further studied, it is known that IRS1 is the major substrate of insulin and IGF1 receptors, which play important roles in bone metabolism (Bikle 2008, Giustina et al. 2008), IRS1 gene silencing in osteoblast obviously inhibited the AKT phosphorylation (Fig. 1), and AKT is the direct target of IGF1 in IRS1 signal pathway. Therefore, we hypothesized that Irs 1 gene silencing hindered insulin and IGF1 signal transduction, which led to reduced cell survival and proliferation and impairment in the differentiation of MC3T3-E1 cells.

Ogata's research (Ogata et al. 2000) indicated that IRS1 was expressed only in the osteoblasts and not in the osteoclasts in wild-type mice; however, bone resorption was decreased in $I r 1^{-1-}$ mice. Osteoblast-derived MMPs function as a coupling factor and play important roles in the bone turnover. MMPs are believed to generate collagen fragments, which are necessary for the recruitment and activation of osteoclasts and the initiation of bone resorption (Holliday et al. 1997, Parikka et al. 2001). We conducted this study to determine whether IRS1 regulates the expression of MMP1, MMP2, MMP3, MMP13, and MMP14 in murine preosteoblastic MC3T3-E1 cells. Our results showed that knocking down Irs 1 decreased the protein levels of MMP2, MMP13, and
MMP14, but had no effect on MMP1 expression. IRS1 is an essential molecule for the intracellular signaling of IGF1 and insulin, which are potent anabolic regulators of bone metabolism, and MMPs are regulators of catabolism; it seems self-contradictory that the silencing of anabolic regulator decreased the expression of regulators of catabolism, but our results were consistent with the study in malignant H-ras transformed cells by Yoon \& Hurta (2001), which showed that IGF1 up-regulated the expression of MMP2, further studies are needed to elucidate how IRS1 regulates the MMP expression in osteoblasts. Except that IRS1 regulated the bone turnover discussed below, it is possible that the absence of proper anabolic regulation will hinder the functions of osteoblasts, which include the synthesis of matrix and matrix degradation enzymes, cell proliferation and differentiation.

MMP1 (collagenase-1) and MMP13 (collagenase-3) can cleave the fibrillar collagens (Kerkvliet et al. 2003); MMP2 (gelatinase-A) can degrade gelatin, laminin, and nidogen, as well as native type I collagen. MMP14 (MT-MMP) acts as a collagenase, and can cleave native type I, II, and III collagens (Luo et al. 2004, Holmbeck et al. 2005). All the abovementioned MMPs can be expressed by osteoblasts, and play important roles in bone resorption. In the present study, silencing IRS1 decreased the expression of MMP2, MMP3, MMP13, and MMP14, which may lead to a reduction in bone resorption.

Key factors in bone remodeling include RANK ligand (RANK), which is an osteoclast differentiation factor and the ligand of TNFRSF11B (Theill et al. 2002) and stimulates bone resorption, and TNFRSF11B inhibits bone resorption. The ratio between these two factors regulates osteoclast formation and activity (Murthy et al. 2009). The expression of RANKL was decreased in the IRS1 $1^{-1}$ osteoblasts, which suggested that IRS1 is one of the molecules upstream of the RANKL/TNFRSF11B pathway (Ogata et al. 2000). In this in vitro study, both RANKL and TNFRSF11B were found to be decreased in cells transfected with IRS1 shRNA. Normally, TNFRSF11B plays its role by binding to RANKL and preventing it from binding to RANK (Boyce \& Xing 2008), the TNFRSF11B and RANKL were down-regulated simultaneously, which may be one of the reasons that led to the decrease in bone turnover in the IRS1 knockout mice. However, bone remodeling appears to be mainly controlled by the balance of RANKL/TNFRSF11B, and it is now thought that the final step in the osteoclast regulatory pathway may be determined by the relative ratio of the RANKL/ TNFRSF11B system (Boyce \& Xing 2008), so we analyzed the ratio of the RANKL/TNFRSF11B after IRS1 silencing in MC3T3-E1 cells and found that IRS1 gene silencing increased the RANKL/TNFRSF11B ratio, which can partly clarify why mice lacking the IRS1 gene showed severe osteopenia in Ogata's research.

In conclusion, we found that the downregulation of IRS1 reduced cell survival and proliferation; decreased the ALP activity; reduced the expression levels of osteocalcin, 
type I collagen, and ratio of TNFRSF11B to RANKL; and suppressed the synthesis of MMP2, MMP3, MMP13, and MMP14 in murine preosteoblastic MC3T3-E1 cells. Therefore, IRS1 not only promotes bone formation but also plays an important role in bone resorption by regulating MMPs, which maintains the normal bone turnover and remodeling.

\section{Declaration of interest}

The authors declare that there is no conflict of interest that could be perceived as prejudicing the impartiality of the research reported.

\section{Funding}

This work was supported by grants from the National Natural Science Foundation of China (No. 30872617 and No. 30400218).

\section{References}

Akune T 2004 The role of insulin receptor substrates in bone metabolism. Clinical Calcium 14 289-292.

Akune T, Ogata N, Hoshi K, Kubota N, Terauchi Y, Tobe K, Takagi H, Azuma Y, Kadowaki T, Nakamura K et al. 2002 Insulin receptor substrate-2 maintains predominance of anabolic function over catabolic function of osteoblasts. Journal of Cell Biology 159 147-156.

Bikle DD 2008 Growth hormone/insulin-like growth factor-1/PTH axis in bone. Journal of Bone and Mineral Research 23 581-583.

Boyce BF \& Xing L 2007 The RANKL/RANK/OPG pathway. Current Osteoporosis Reports 5 98-104.

Boyce BF \& Xing L 2008 Functions of RANKL/RANK/OPG in bone modeling and remodeling. Archives of Biochemistry and Biophysics $\mathbf{4 7 3}$ 139-146.

Bu YH, Peng D, Zhou HD, Huang QX, Liu W, Luo XB, Tang LL \& Tang AG 2009 Insulin receptor substrate 2 plays important roles in $17 \beta$-estradiol induced bone formation. Journal of Endocrinological Investigation 32 682-689.

Burks DJ \& White MF 2001 IRS proteins and cell function. Diabetes 50 S140-S145.

Cusi K, Maezono K, Osman A, Pendergrass M, Patti ME, Pratipanawatr T, DeFronzo RA, Kahn CR \& Mandarino LJ 2000 Insulin resistance differentially affects the PI3-kinase and MAP kinase-mediated signaling in human muscle. Journal of Clinical Investigation 105 311-320.

Gallagher JC 2008 Advances in bone biology and new treatments for bone loss. Maturitas $6065-69$.

Giustina A, Mazziotti G \& Canalis E 2008 Growth hormone, insulin-like growth factors and the skeleton. Endocrine Reviews 29 535-559.

Hamdy NA 2007 Targeting the RANK/RANKL/OPG signaling pathway: a novel approach in the management of osteoporosis. Current Opinion in Investigational Drugs 8 299-303.

Holliday LS, Welgus HG, Fliszar CJ, Veith GM, Jeffrey JJ \& Gluck SL 1997 Initiation of osteoclast bone resorption by interstitial collagenase. Journal of Biological Chemistry 272 22053-22058.

Holmbeck K, Bianco P, Pidoux I, Inoue S, Billinghurst RC, Wu W, Chrysovergis K, Yamada S, Birkedal-Hansen H \& Poole AR 2005 The metalloproteinase MT1-MMP is required for normal development and maintenance of osteocyte processes in bone. Journal of Cell Science $\mathbf{1 1 8}$ $147-156$

Kadowaki T, Tobe K, Honda-Yamamoto R, Tamemoto H, Kaburagi Y, Momomura K, Ueki K, Takahashi Y, Yamauchi T \& Akanuma Y 1996 Signal transduction mechanism of insulin and insulin-like growth factor-1. Endocrine Journal 43 S33-S41.
Kearns AE, Khosla S \& Kostenuik PJ 2008 Receptor activator of nuclear factor kappaB ligand and osteoprotegerin regulation of bone remodeling in health and disease. Endocrine Reviews 29 155-192.

Kerkvliet EH, Jansen IC, Schoenmaker T, Beertsen W \& Everts V 2003 Collagen type I, III and V differently modulate synthesis and activation of matrix metalloproteinases by cultured rabbit periosteal fibroblasts. Matrix Biology 22 217-227.

Li J, Liao EY, Dai RC, Wei QY \& Luo XH 2004 Effects of $17 \beta$-estradiol on the expression of interstitial collagenases -8 and -13 (MMP-8 and MMP-13) and tissue inhibitor of metalloproteinase-1 (TIMP-1) in ovariectomized rat osteoblastic cells. Journal of Molecular Histology 35 723-731.

Luo XH, Liao EY, Su X \& Wu XP 2004 Parathyroid hormone inhibits the expression of membrane-type matrix metalloproteinase-1 (MT1-MMP) in osteoblast-like MG-63 cells. Journal of Bone and Mineral Research 22 19-25.

Manduca P, Castagnino A, Lombardini D, Marchisio S, Soldano S, Ulivi V, Zanotti S, Garbi C, Ferrari N \& Palmieri D 2009 Role of MT1-MMP in the osteogenic differentiation. Bone 44 251-265.

Murthy RK, Morrow PK \& Theriault RL 2009 Bone biology and the role of the RANK ligand pathway. Oncology 23 9-15.

Ogata N, Chikazu D, Kubota N, Terauchi Y, Tobe K, Azuma Y, Ohta T, Kadowaki T, Nakamura K \& Kawaguchi H 2000 Insulin receptor substrate-1 in osteoblast is indispensable for maintaining bone turnover. Journal of Clinical Investigation 105 935-943.

Parikka V, Lehenkari P, Sassi ML, Halleen J, Risteli J, Härkönen P \& Väänänen HK 2001 Estrogen reduces the depth of resorption pits by disturbing the organic bone matrix degradation activity of mature osteoclasts. Endocrinology 142 5371-5378.

Ra HJ \& Parks WC 2007 Control of matrix metalloproteinase catalytic activity. Matrix Biology 26 587-596.

Rifas L, Fausto A, Scott MJ, Avioli LV \& Welgus HG 1994 Expression of metalloproteinase and tissue inhibitor of metalloproteinase in human osteoblast-like cells: metalloproteinase biosynthesis. Endocrinology 134 213-221.

Rowe DJ, Ko S, Tom XM, Silverstein SJ \& Richards DW 1999 Enhanced production of mineralized nodules and collagenous proteins in vitro by calcium ascorbate supplemented with vitamin C metabolites. Journal of Periodontology 70 992-999.

Sun XJ, Rothenberg P, Kahn CR, Backer JM, Araki E, Wilden PA, Cahill DA, Goldstein BJ \& White MF 1991 Structure of the insulin receptor substrate IRS-1 defines a unique signal transduction protein. Nature 352 73-77.

Sun XJ, Wang LM, Zhang Y, Yenush L, Myers MG, Glasheen E, Lane WS, Pierce JH \& White MF 1995 Role of IRS-2 in insulin and cytokine signaling. Nature 377 173-177.

Theill LE, Boyle WJ \& Penninger JM 2002 RANK-L and RANK: T cells, bone loss, and mammalian evolution. Annual Review of Immunology 20 795-823.

Webber MM 1980 Growth and maintenance of normal prostatic epithelium in vitro - a human cell model. Progress in Clinical and Biological Research 37 181-216.

Yamaguchi M \& Uchiyama S 2004 Receptor activator of NF-kappaB ligand-stimulated osteoclastogenesis in mouse marrow culture is suppressed by zinc in vitro. International Journal of Molecular Medicine 14 81-85.

Yoon A \& Hurta RA 2001 Insulin like growth factor-1 selectively regulates the expression of matrix metalloproteinase- 2 in malignant $\mathrm{H}$-ras transformed cells. Molecular and Cellular Biochemistry 223 1-6.

Received in final form 23 May 2010

Accepted 4 June 2010

Made available online as an Accepted Preprint 4 June 2010 